\title{
Mallory-Weiss Syndrome
}

National Cancer Institute

\section{Source}

National Cancer Institute. Mallory-Weiss Syndrome. NCI Thesaurus. Code C84881.

A disorder characterized by upper gastrointestinal tract bleeding caused by longitudinal mucosal tears in the gastroesophageal junction. The tears result from retching or forceful coughing. It was initially described in alcoholics. 